\title{
21. PLEISTOCENE CLIMATIC CHANGES AS DEDUCED FROM A POLLEN ANALYSIS OF SITE 717 CORES 1
}

\author{
Yoshinori Yasuda, ${ }^{2}$ Kazuo Amano, ${ }^{3}$ and Tohru Yamanoi ${ }^{4}$
}

\section{INTRODUCTION}

Pollen from marine sediment has been used to the study of monsoon fluctuations in the Arabian Sea (Van Campo et al., 1982; Van Campo, 1986) and off the northwest African coast (Hooghiemstra, 1988). These studies reveal major changes in the monsoon cycle since the last interglacial period. However, fluctuations before $120 \mathrm{k} . \mathrm{y}$. B.P. remain unclear. In this report, we document a dramatic climatic change that occurred around the beginning of the middle Pleistocene in the Bay of Bengal, based mainly on the results of pollen analysis from ODP Site 717 cores.

ODP Site 717 cores were recovered from the tip of the Bengal deep sea fan. The site $\left(0^{\circ} 55^{\prime} \mathrm{S}, 81^{\circ} 23^{\prime} \mathrm{E}\right)$ is located about $700 \mathrm{~km}$ south of Sri Lanka (Fig. 1). Alam (1989) distinguishes two major phases of sedimentation within the Bengal Basin and pointed out that the second major phase started in the middle Miocene. It is generally assumed that sedimentation of the Bengal deep sea fan was strongly influenced by the uplift and erosion of the Himalayas. Sedimentation of palynomorphs was also influenced by river transport of the Ganges, Brahmaputra, and Irrawaddy Rivers.

The Bengal Basin is characterized by a very pronounced monsoon circulation system, with a northeast monsoon in winter and a southwest monsoon in summer (Figs. 1,2). These winds are largely responsible for the transportation of windborne pollen in the area. Surface water circulation in the Bengal Bay and Andaman Sea is also dependent on the monsoonal wind patterns. During the northeast (winter) monsoon, a North Equatorial Current appears, while during the southwest (summer) monsoon, a Southwest Monsoon Current develops (Figs. 1, 2). These water currents influence the transportation and deposition of pollen and spores in the sediments on the ocean floor (Figs. 1,2).

Due to the scarcity of wind-pollinated flowers, the very rich flora of the tropical rain forest is poorly preserved in the marine sediments. Mangrove pollen is, however, well preserved, because the major palynomorphs are transported by river and surface water currents. The distribution of mangrove swamps in the coastal area of the Bengal Bay and Andaman Sea is shown in Figure 1.

\section{METHOD}

In this report, we discuss the results of pollen analysis from the upper $200 \mathrm{~m}$ of cores from ODP Site 717. Nannofossil biostratigraphy yielded two age data within this interval, i.e., 470 k.y. B.P. at 67.5 mbsf and 930 k.y. B.P. at 198 mbsf (Cochran, Stow, et al., 1989). Thus the upper $200 \mathrm{~m}$ of Site 717 sediments span about $1 \mathrm{Ma}$.

\footnotetext{
${ }^{1}$ Cochran, J. R., Stow, D.A.V., et al., 1990. Proc. ODP, Sci. Results, 116: College Station, TX (Ocean Drilling Program).

2 International Research Center for Japanese Studies, Kyoto, Japan.

${ }^{3}$ Department of Earth Science, Ibaragi University, Mito, Japan.

${ }^{4}$ Faculty of General Education, Yamagata University. Yamagata, Japan.
}

An additional age constraint is a tenuous interpretation that the upper $150 \mathrm{~m}$ of core display a normal polarity acquired during the Brunhes chron (Cochran, Stow, et al. 1989). This suggests an age of 730 k.y. B.P. for $150 \mathrm{mbsf}$, in relatively good agreement with a value of 141 mbsf predicted by interpolation between the biostratigraphic age data.

Palynomorphs were separated from the sediment matrix by the heavy liquid flotation method modified from Faegri and Iversen (1964). The processing sequence is as follows; measuring wet volume; HCL $(10 \%)$ treatment; wash (in distilled water); sieve (through a 60 mesh sieve); wash; float (zinc chloride heavy liquid flotation; specific gravity 2.1 ); HCL (1\%) treatment; wash; dehydration (acetic acid); acetolysis (boiled for $3 \mathrm{~min}$ in water basin in a solution of 1 part concentrated sulfuric acid and 9 parts acetic anhydride); dehydration; wash; mount.

The material was examined at $400 \times$ and when necessary, oil immersion was used. Generally more than 200 pollen grains were identified in each sample.

As well as observations using light microscope, the samples were also studied using a scanning electron microscope (SEM). Residual materials were fixed by Carnoy's fluid (3 parts ethyl alcohol and 1 part acetic acid) for $1 \mathrm{hr}$. The fixed material was washed with ethyl alcohol and then fixed by isoamylacetate for 30 min. A drop of the material was then put on a brass stage and allowed to dry naturally, and then coated using an by Au-Pd target for $2 \mathrm{~min}$ in the Ion Sputter Fine Coat.

A pollen diagram (Figs. 3, 4) was constructed in terms of percentages of the total pollen. Representative fossil pollen and spores are shown in Plates 1-4.

\section{RESULTS OF POLLEN ANALYSIS}

Euphorbiaceae, Gramineae, Cyperaceae, and spores show high concentrations throughout the pollen diagram. Based on the frequencies of characteristic species, the pollen diagram for the upper part of the ODP Site 717 cores were divided into three local pollen zones, $\mathrm{X}, \mathrm{Y}$, and $\mathrm{Z}$ from the bottom of the core upward (Figs. 3, 4).

Zone X: This zone is characterized by high values of Podocarpus, Pentacea, Clidenia, Meliaceae, Acanthaceae, and Gramineae, suggesting warm climate. Podocarpus is distributed widely in Southeast Asia, East Australia, East Africa, and South America (Fig. 2) and is one of the typical species of the Southern Hemisphere. Fossils of Podocarpus before the Eocene period have been reported from India (Fig. 2). It has been suggested that prior to the Eocene there was a Podocarpus forest in India and the coastal area of Arabia. Podocarpus subsequently became reduced in India due to the deterioration in the climate. It is interesting to note that Podocarpus still shows high concentrations in the lower part of pollen Zone $\mathrm{X}$, indicating the existence of a Podocarpus forest. We suppose that a Podocarpus forest still remained in India as late as early Pleistocene and the pollen were transported by southwest monsoon into the Andaman Sea. 


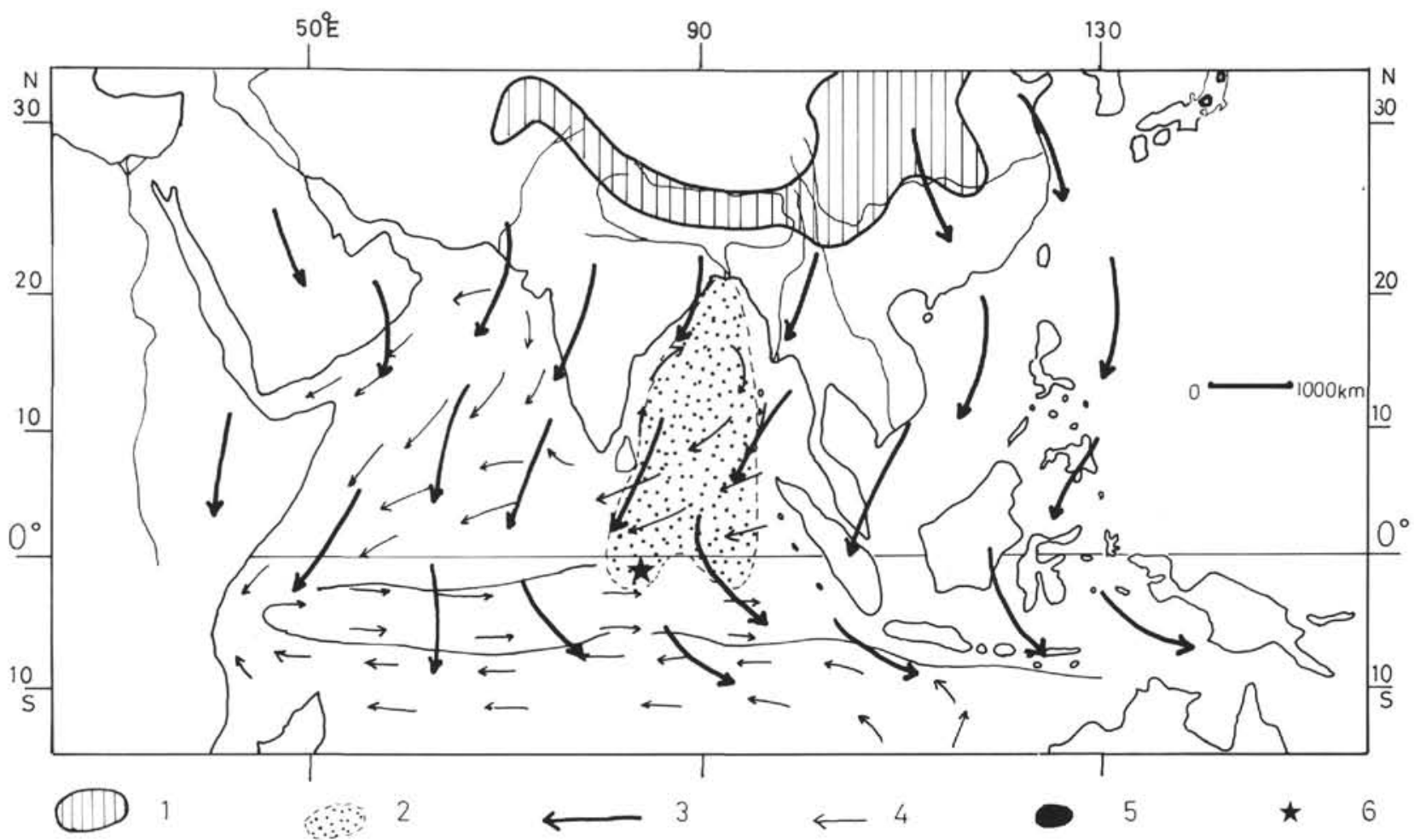

Figure 1. Map showing the distribution of Picea (after Hotta, 1974), the prevailing wind direction in January (after Kurashima, 1966), the Bengal deep sea fan (after Alam, 1989), the surface water circulation in February (after Koizumi, 1987), and the ODP Site 717. 1. Distributional area of Picea, 2. Bengal deep sea fan, 3. Prevailing wind direction, 4. Surface ocean currents in February, 5. Mangrove swamp, 6. The ODP Site 717.

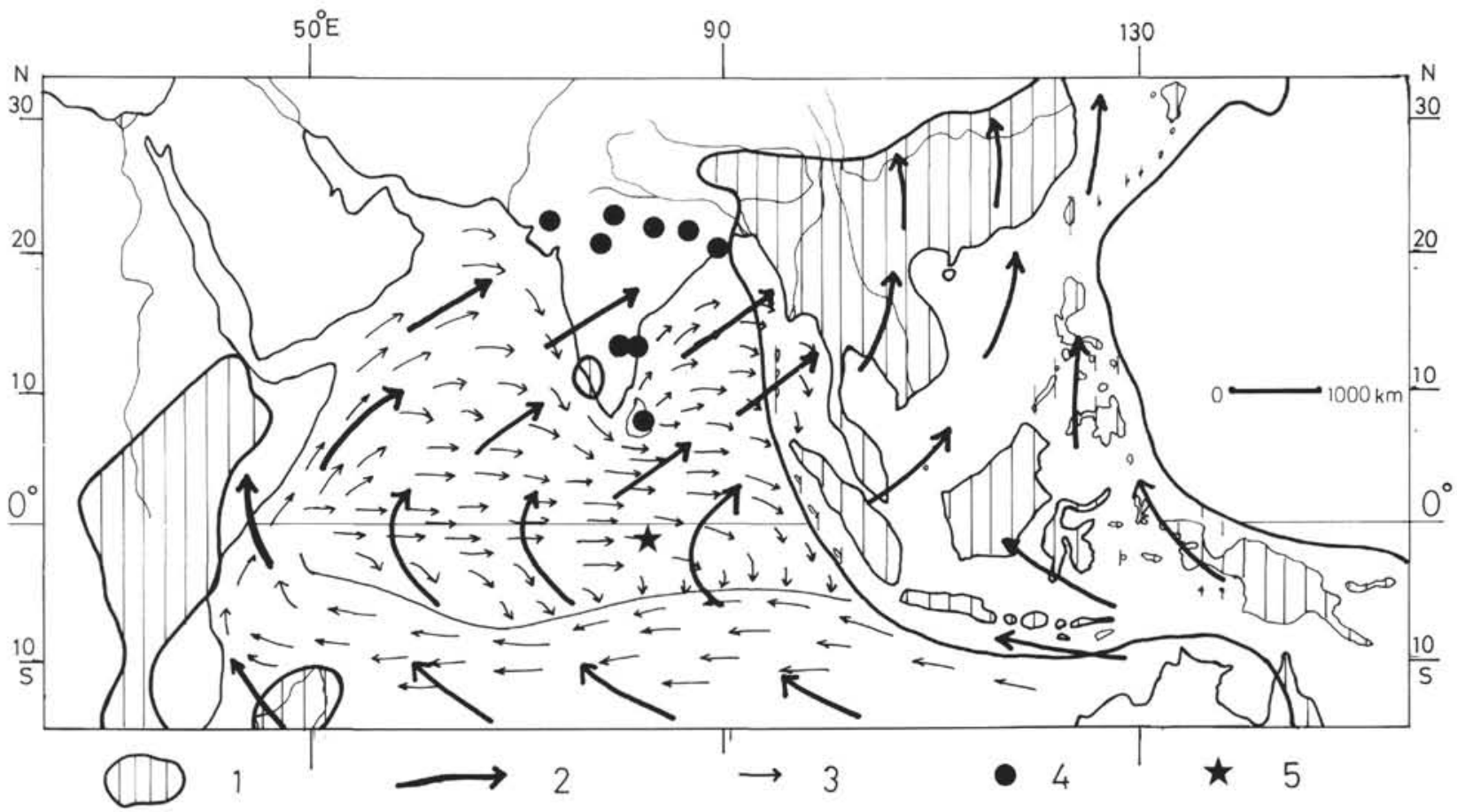

Figure 2. Map showing the distribution of Podocarpus (after Hotta, 1974), the prevailing wind direction in July (after Kurashima, 1966), the surface ocean current in August (after Koizumi, 1987), the fossil records of Podocarpus before Eocene (after Hotta, 1974), and the ODP Site 717. 1. Distributional area of Podocarpus, 2. Prevailing wind direction in July, 3. Surface ocean current in August, 4. Fossil records of Podocarpus before Eocene, 5. The ODP Site 717. 


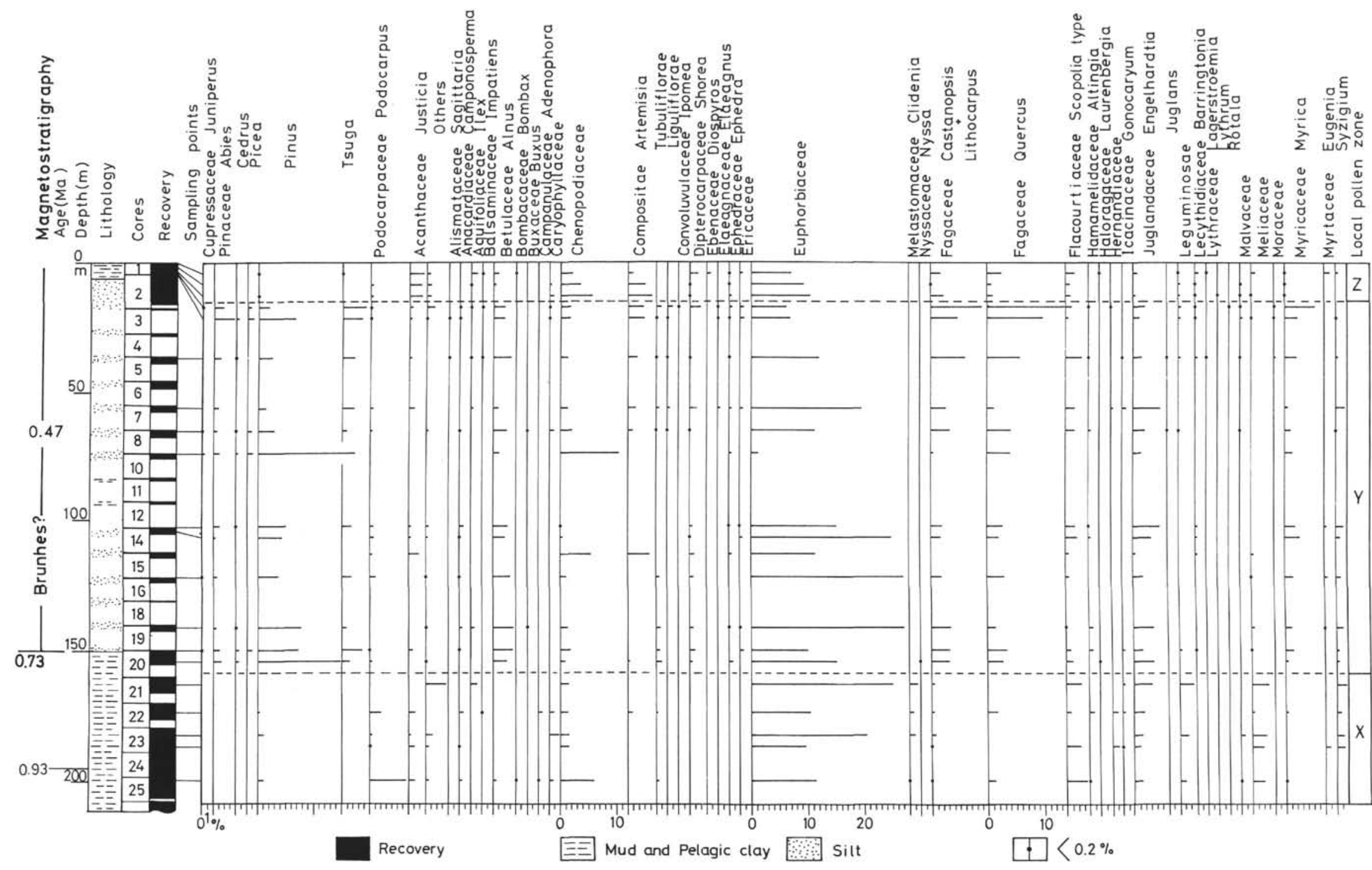

Figure 3. Pollen diagram from the ODP Site 717. 

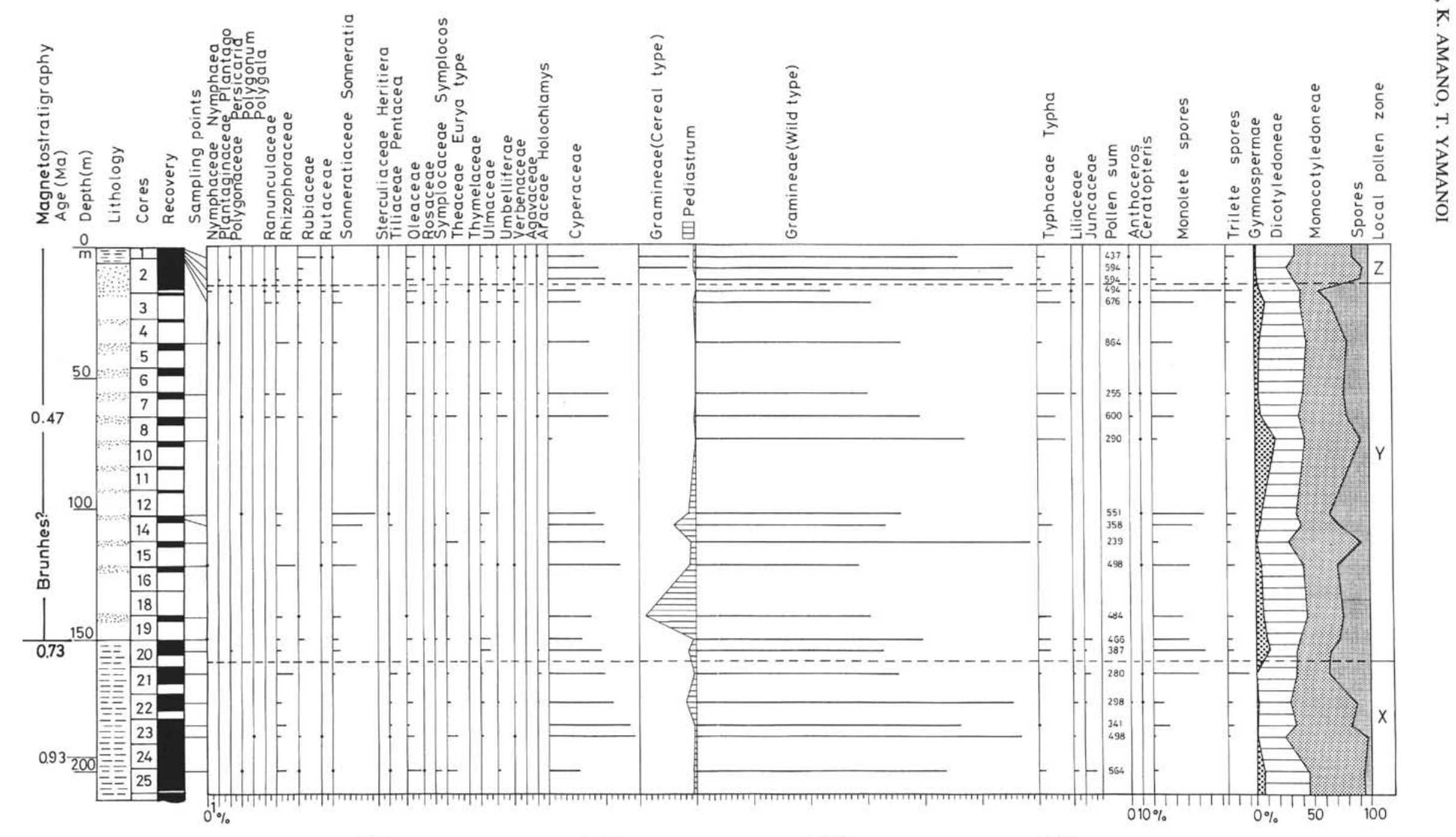

济Gymnospermae $\quad$ Dicotyledoneae $\quad$ Monocotyledoneae $\square$ spores

Figure 4. Pollen diagram from the ODP Site 717. 
Zone Y: This zone is characterized by a notable increase in Pinus and the appearance of Abies, Cedrus, Picea, and Tsuga, and a decrease of Podocarpus. Tsuga, Abies, and Picea presently grow in the Himalayas at an altitude more than 2100 $\mathrm{m}$ and are characteristic species for the Northern Hemisphere (Fig. 1).

A decrease of Podocarpus, Acanthaceae, Meliaceae, and Clidenia and increase of Pinus, Picea, Abies, and Tsuga indicate that the climate became colder. Alnus, Castanopsis or Lithocarpus, Quercus, Myrica, Engelhardtia, Barringtonia, Sonneratia, Ulmaceae, Myrica, and monolete spores also increase. These dramatic vegetational changes happened at about the beginning of the middle Pleistocene. The remarkable increase of Pinus and the appearance of Picea, Abies, and Tsuga indicate that the climate became cold.

Another characteristic feature of Zone $\mathrm{Y}$ is a remarkable increase of Sonneratia, Typha, and Pediastrum. Two types of fossil pollen of Sonneratia can be distinguished, $S$. alba and $S$. caseolaris. $S$. caseolaris grows in a brackish environment (Chapman, 1976). The appearance of $S$. caseolaris and rapid increase of Pediastrum indicate a strong fluvial influences in deposition. The sediment matrix of the Zone Y is mainly composed of silt and marks an increase in grain size compared with Zone X. A noticeable increase of Sonneratia and Pediastrum associated with swamp forest pollen like Alnus and Typha indicate that a large proportion of the palynomorphs were transported from the Bengal coast by the northeast monsoon, Northern Equatorial Current and in suspension in the rivers. The increase of grain size in the sediment corresponds closely to the remarkable increase of Pinus and appearance of Abies, Picea, and Tsuga, although the changes in the palynomorphs took place slightly earlier than the increase of grain size in the sediment. Increase of grain size in the sediment matrix might be caused by the development of glaciation in the Himalayas in the cold climate, producing a large amount of debris. Eroded material would be transported by the Ganges and Brahmaputra Rivers into the Bay of Bengal.

Unfortunately recovery of the upper $200 \mathrm{~m}$ of the Site 717 cores are poor, so that we could not reconstruct the detailed climatic changes after the beginning of the middle Pleistocene, however, we can say that the climate became cold after middle Pleistocene and that therefore the monsoon circulation must have changed dramatically.

Zone $\mathrm{Z}$ : This zone is recognized by the sudden decrease of Pinus, Abies, and Tsuga. There is a similar but less dramatic decrease in Alnus, Castanopsis, or Lithocarpus, Quercus, Engelharditia, Myrica, Sonneratia, Ulmaceae, Typha, and spores, while Acanthaceae, Chenopodiaceae, and Gramineae increase. This zone may be Holocene and indicates a warm climate.

\section{CONCLUSIONS}

Studies of the pollen content of the upper $200 \mathrm{~m}$ of the ODP Site 717 core from the Bengal deep sea fan reveals a major climatic change occurred around the beginning of the middle Pleistocene. Before this time, climate was warm and southwest monsoon circulation was dominant. Afterward, the climate became cold and the glaciation developed in the Himalayas producing a large amount of debris. The sediment matrix of the ODP Site 717 cores are coarser after the beginning of the middle Pleistocene, suggesting an increase in the grain size of suspended matter of the Ganges, Brahmaputra, and Irrawaddy Rivers. This can also be related to the postulated period of glaciation based on the pollen analytical studies.

A remarkable increase of Pinus with the appearance of Picea, Abies, and Tsuga suggests the dominance of a northeast monsoon transporting palynomorphs from the foot of the Himalayas. After this time, mangrove pollen Sonneratia and Pediastrum increased,indicating the development of the North Equatorial Current and the strong influence of the suspended matter of the river. The documented dramatic climatic changes imply that there was also a corresponding change in the monsoon circulation of the area.

\section{REFERENCES}

Alam, M., 1989. Geology and depositional history of Cenozoic sediments of the Bengal basin of Bangladesh. Palaeogeogr., Palaeoclimatol., Palaeoecol., 69:125-139.

Chapman, V. J., 1976. Mangrove Vegetation: Vaduz (J. Cramer), 104-144.

Cochran, J. R., Stow, D.A.V., et al., 1989. Proc. ODP, Init. Repts., 116: College Station, TX (Ocean Drilling Program).

Faegri, K., and Iversen, J., 1964. Textbook of pollen analysis: New York (Hafner Press).

Hooghiemstra, H., 1989. Changes of major wind belts and vegetation zones in NW Africa 20,000-5000 YR B.P., as deduced from a marine pollen record near Cap Blanc. Rev. Palaeobot. Palynol., 55:101-140.

Hotta, M., 1974. Evolution Biology in Plants III: History and Geography of Plants: Tokyo (Sanseido).

Koizumi, I., 1987. Micro fossils as the indicators of palaeoclimate and palaeoocean current. Gekkan Chikyu, 102:712-719.

Kurashima, A., 1966. Climate of Japan: Tokyo (Kokonshoin).

Van Campo, E., 1986. Monsoon fluctuations in two 20,000-Yr B.P.Oxygen-isotope pollen records off southwest India. Quat. Res., 26:376388.

Van Campo, E., Duplessy, J. C., and Rossignol-Strict, M., 1982. Climatic conditions deduced from a 150 -kyr oxygen isotope pollen record from the Arabian sea. Nature, 296:56-59.

Date of initial receipt: 28 June 1989

Date of acceptance: 6 February 1990

Ms 116B-130 


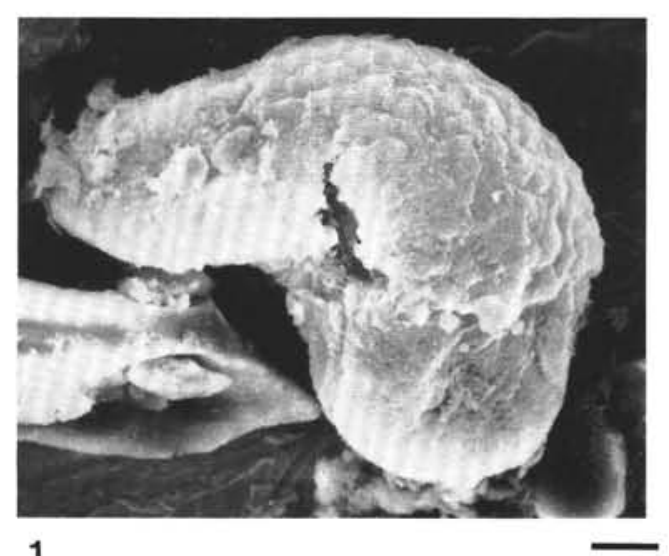

1

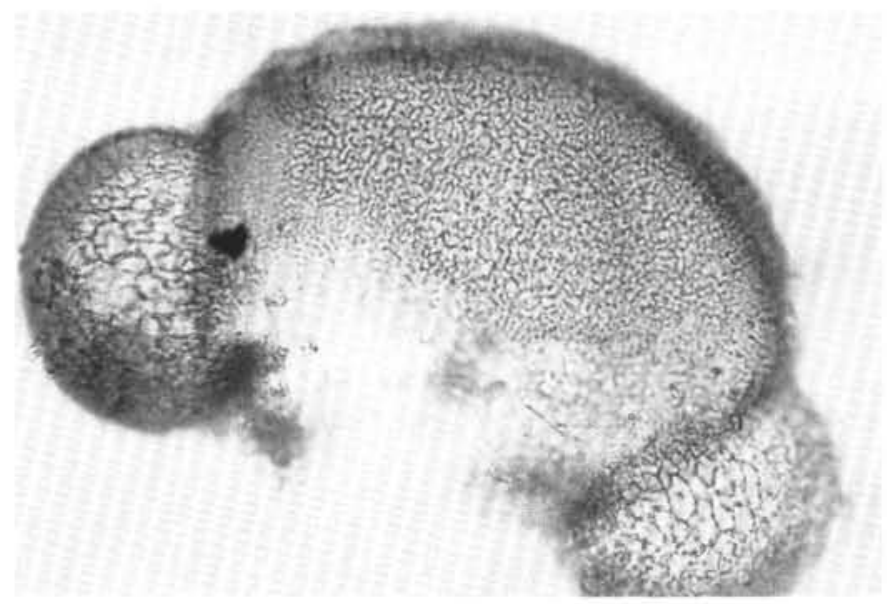

3

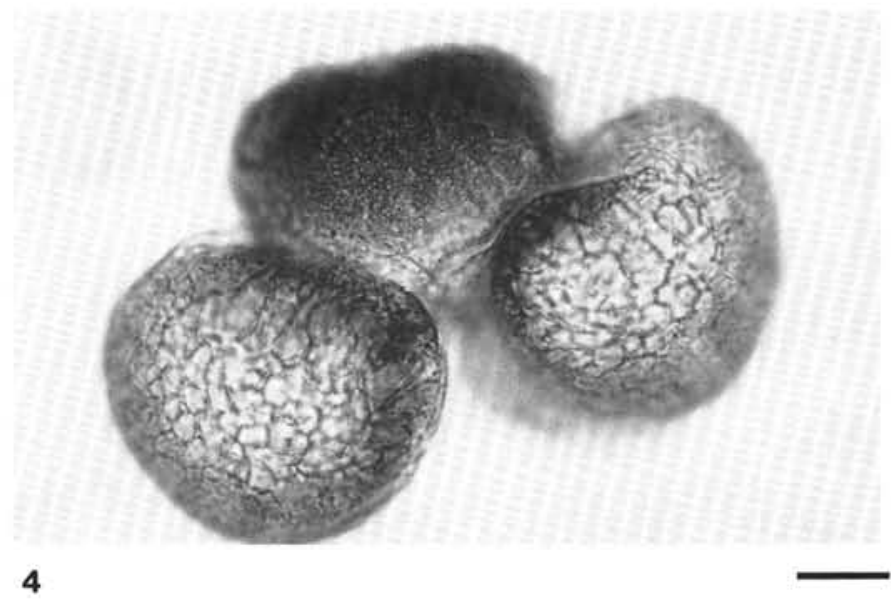

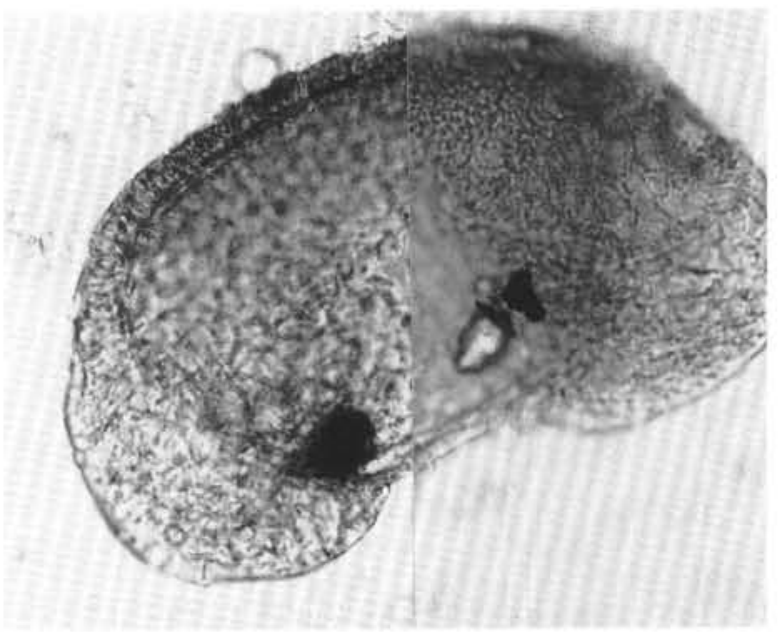

2

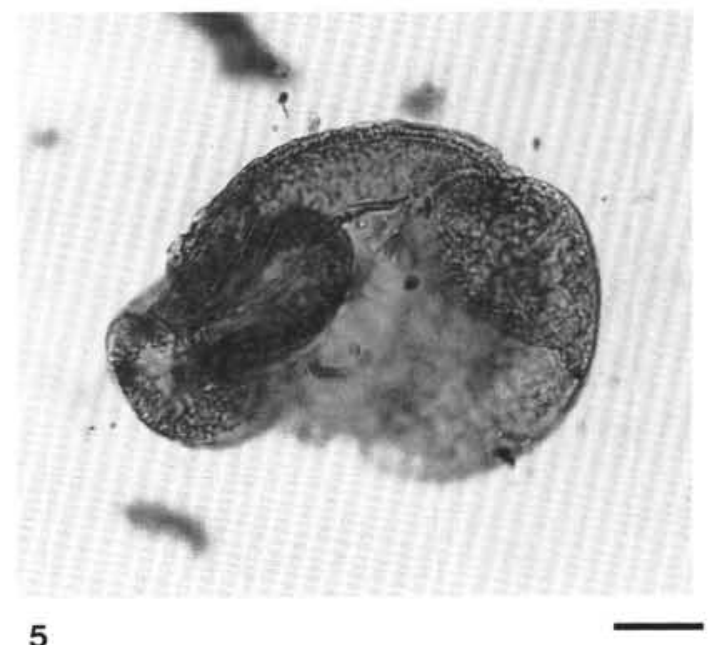

5

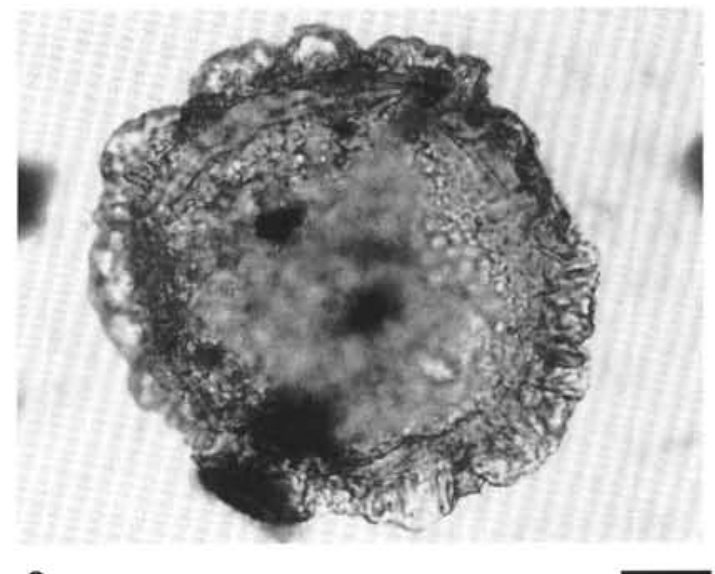

6

Plate 1. Fossil pollen from ODP Site 717 cores. 1. Cedrus deodara (SEM). 2. Cedrus deodara (LM). 3, 4. Abies (LM). 5. Pinus (LM). 6. Tsuga (LM). Bar is $10 \mu \mathrm{m}$. 

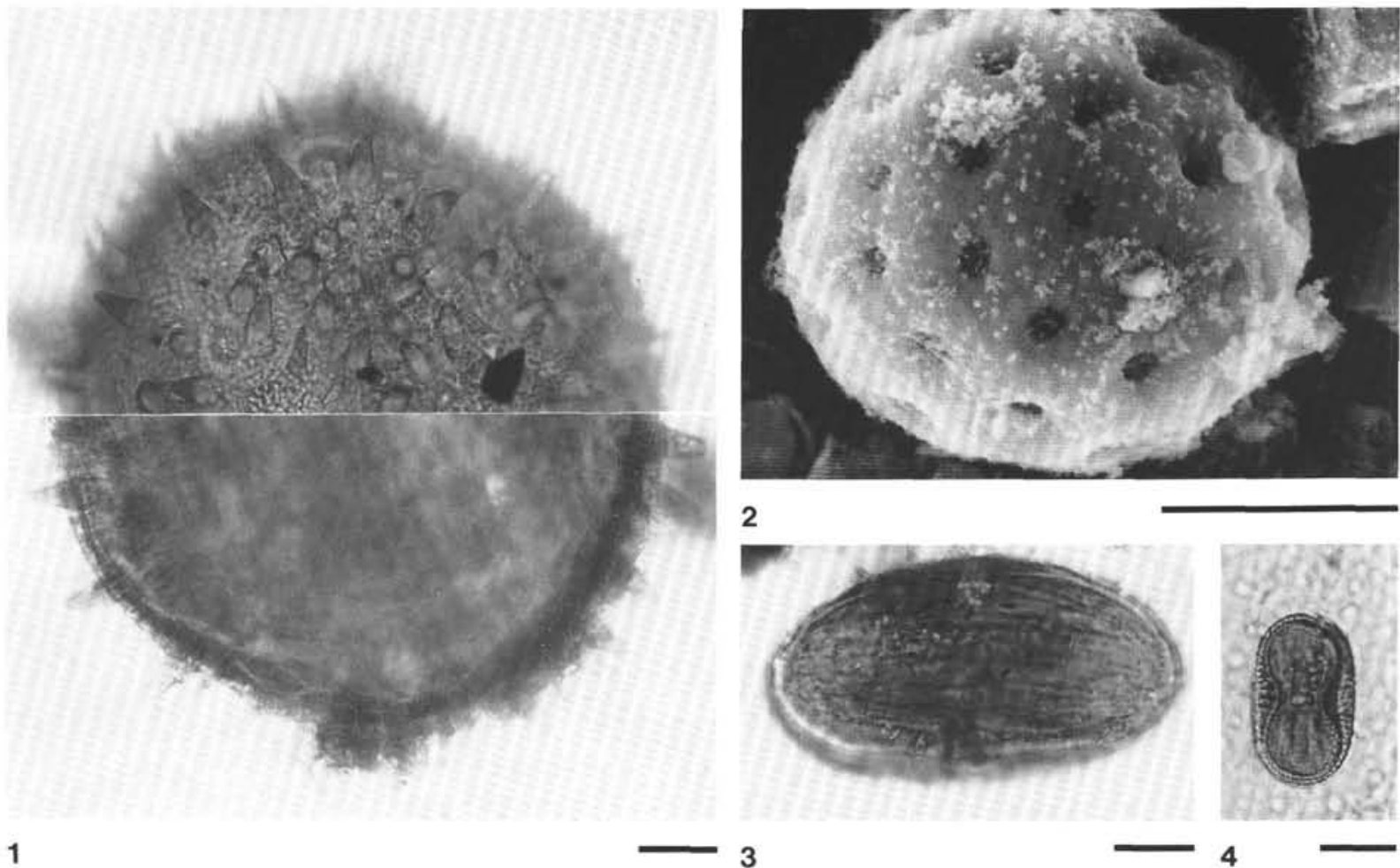

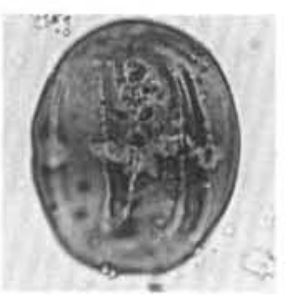

5

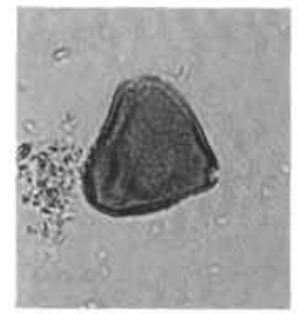

10

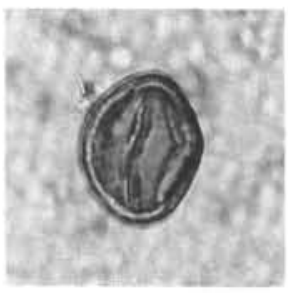

6

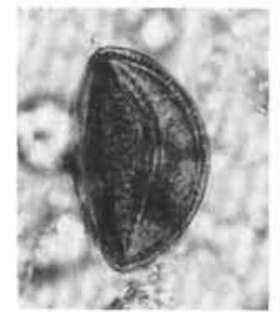

11

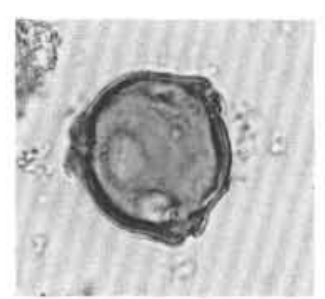

7

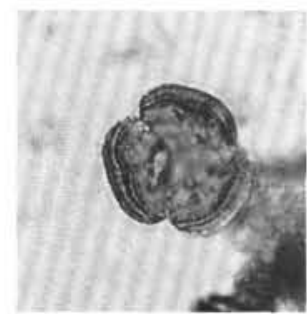

12

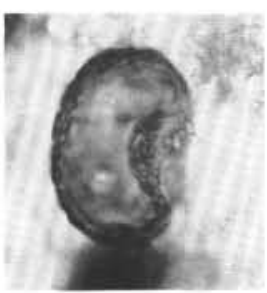

8

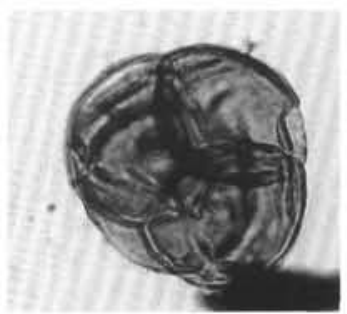

13

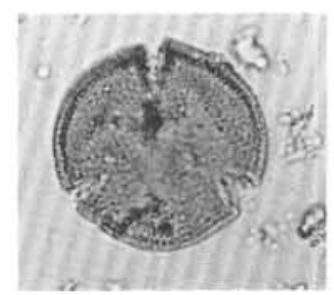

9

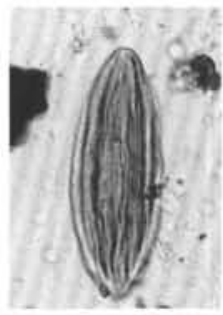

$14 \overline{5 \sim 14}$

Plate 2. Fossil pollen from ODP Site 717 cores. 1. Malvaceae (LM). 2. Chenopodiaceae (LM). 3, 4. Acanthaceae (LM). 5. Meliaceae (LM). 6. Quercus (LM). 7. Myricaceae (LM). 8. Ulmaceae (LM). 9. Pentacea (LM). 10. Symplocos (LM). 11. Euphorbiaceae (LM). 12. Artemisia (LM). 13. Ericaceae (LM). 14. Ephedra (LM). Bar is $10 \mu \mathrm{m}$. 

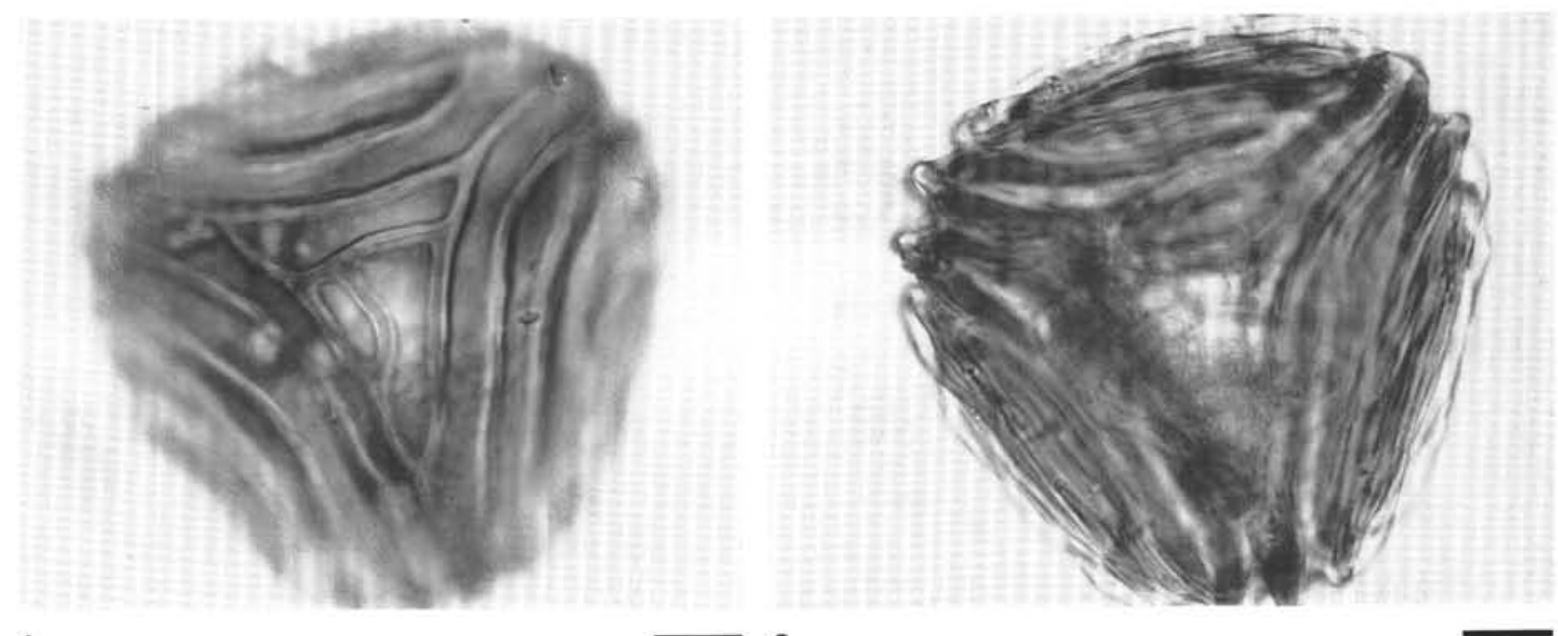

1
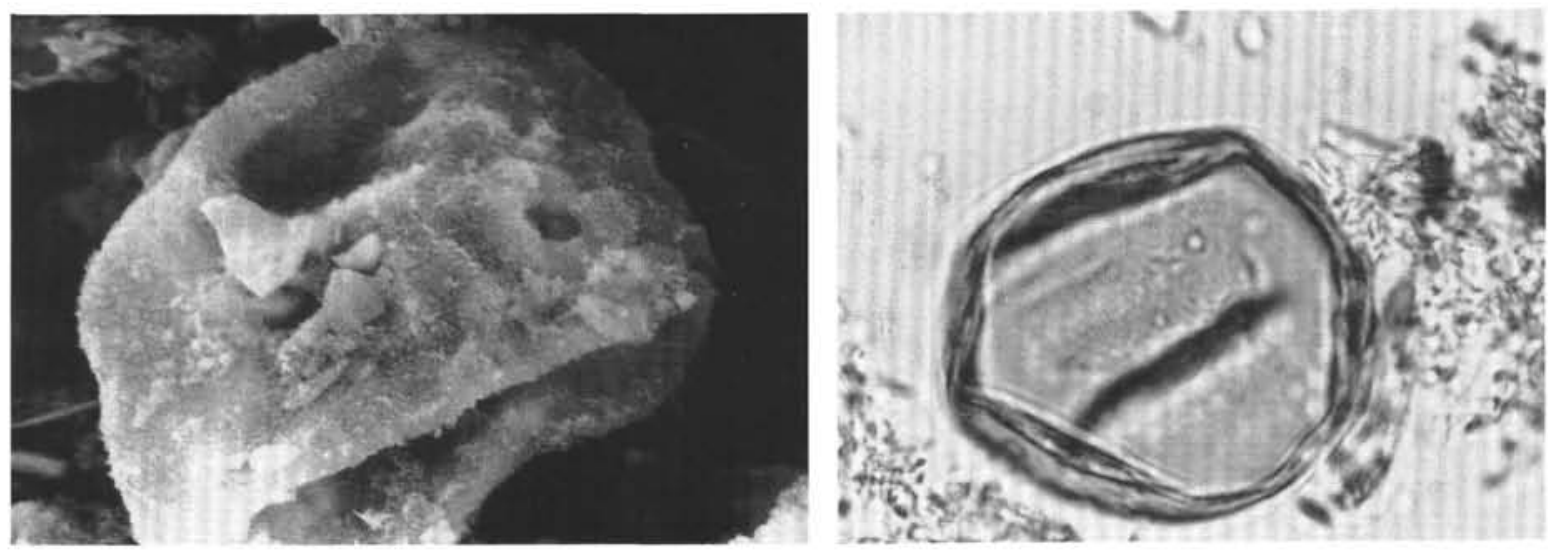

\section{3}
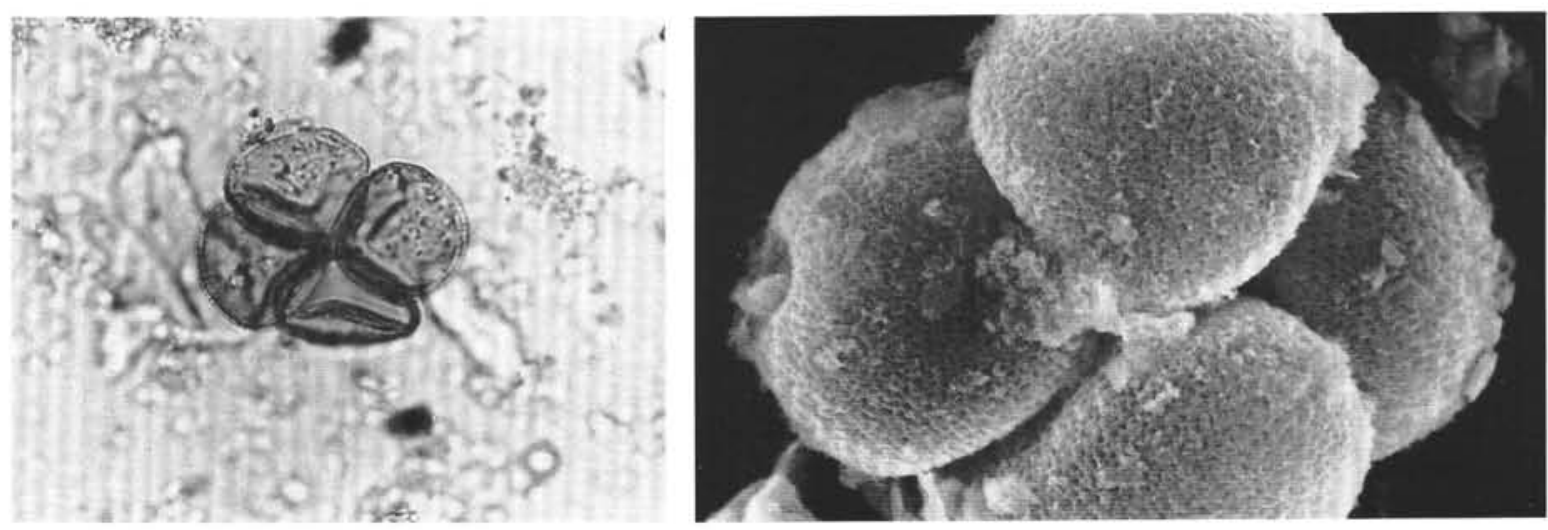

Plate 3. Fossil pollen and spores from ODP Site 717 cores. 1, 2. Ceratopteris (LM). 3. Gramineae (SEM). 4. Gramineae (LM). 5. Typha (LM). 6. Typha (SEM). Bar is $10 \mu \mathrm{m}$. 

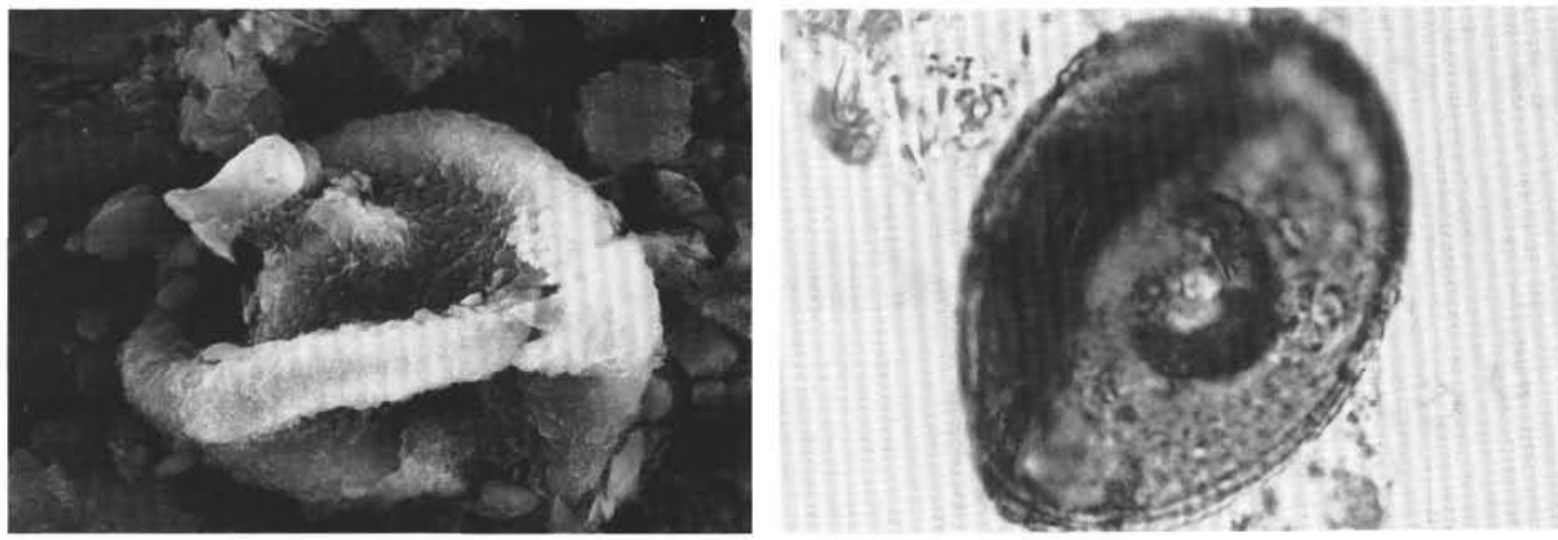

1

\section{2}
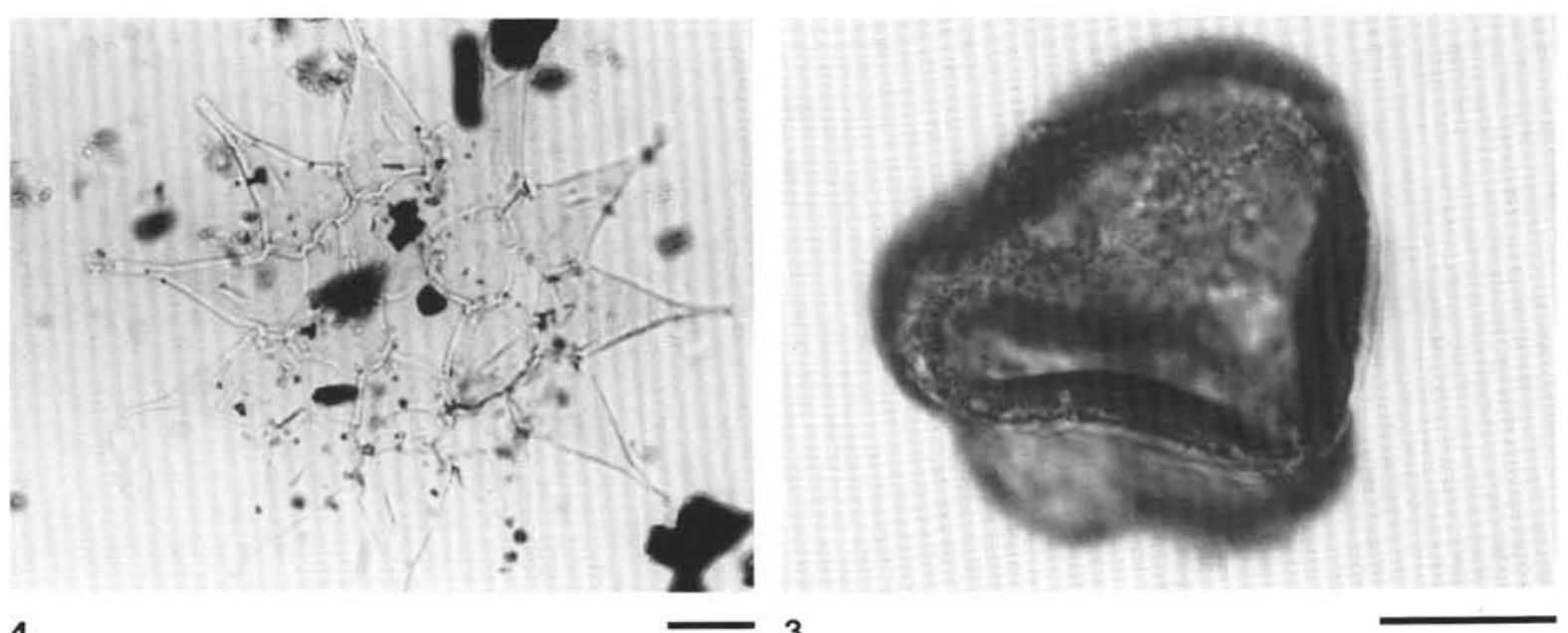

4

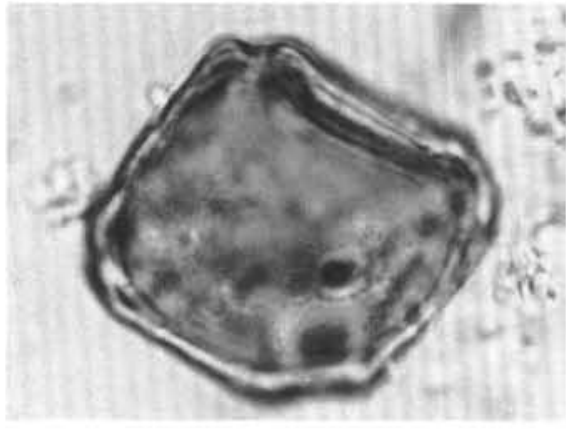

5
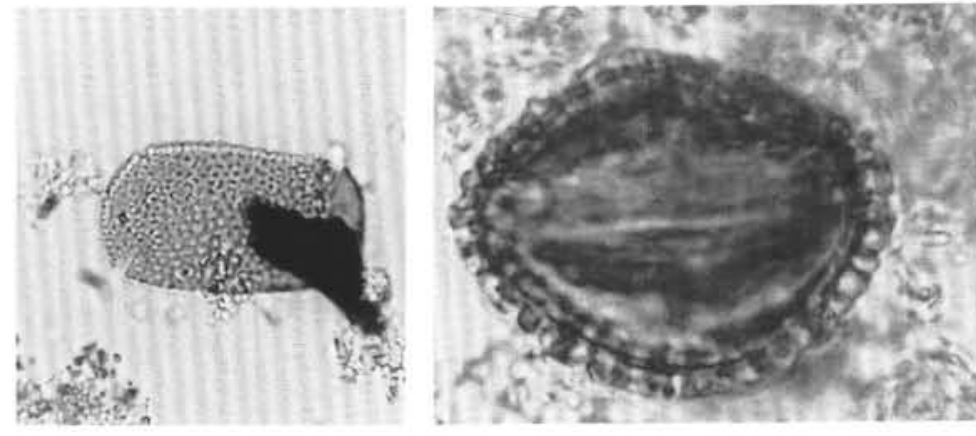

Plate 4. Fossil pollen and Pediastrum from ODP Site 717 cores. 1. Sonneratia (SEM). 2, 3. Sonneratia (LM). 4. Pediastrum (LM). 5. Alnus (LM). 6. Impatiens (LM). 7. Ilex (LM). Bar is $10 \mu \mathrm{m}$. 